\title{
Spectral analyses of movements made by the cephalic appendages of copepods
}

\author{
S. A. Poulet, C. W. Gill \\ Station d'Océanologie et de Biologie Marine, CNRS, Place Teissier, F-29211 Roscoff, France
}

\begin{abstract}
Movements of Calanus helgolandicus, Centropages typicus and Temora longicornis cephalic appendages, which are involved in feeding and swimming, were investigated. When considered together, results of limb beat traces and of spectral and autocorrelation analyses show that the movements of copepods cephalic limbs are dependent upon the species, and are indicative of sensory feeding behaviour. T. longicornis exposed to mechanosensory stimulation, in the form of Sephadex beads, phytoplankton cells or natural particles, produced appendage-movement traces varying in beat frequency and amplitude. Particle size had the greatest influence on appendage movements. Chemical stimulation in the absence of particles (dissolved free amino acid cocktails) generally increased the appendage beat frequency, but did not cause fluctuations in beat amplitude such as occurred with particles. Analyses of the movements of the first maxillae indicate that for filter-feeding calanoid copepods, mechanoreception contributes to particle handling, and chemoreception contributes both to an increase in the speed of the feeding current and the recognition of food. During feeding in copepods, it is likely that mechano- and chemoreception are complementary and act in conjunction.
\end{abstract}

\section{INTRODUCTION}

Since 1980, our understanding of copepod behaviour has increased as a result of ciné techniques pioneered by Alcaraz et al. (1980) and subsequent quantification of such observations using frame motion analysis (Cowles \& Strickler 1983). Information obtained with these techniques (Koehl \& Strickler 1981, Paffenhöfer et al. 1982, Strickler 1982, Price et al. 1983, Price \& Paffenhöfer 1984, 1985, 1986, Vanderploeg \& Paffenhöfer 1985) has produced an end to the controversy over whether particle feeding in copepods is a selective and behavioural process or due to passive mechanical filtration (e.g. Boyd 1976, Frost 1977, Poulet \& Marsot. 1978, Donaghay \& Small 1979). Confirmation and clarification have been obtained of earlier studies which suggested selective and behavioural feeding, but which were made with indirect techniques such as Coulter Counter measurements (e.g. Parsons et al. 1967, Poulet 1978), cell counting under a microscope (e.g. Huntley et al. 1983) or visual observations (e.g. Esterly 1916, Cannon 1928, Conover 1966). Moreover it has been shown that cephalic appendages involved in the feeding process exhibit complex behaviour (Koehl \& Strickler 1981, Price et al. 1983).

It is now generally accepted that appendage move- ments are used to make water movements, for transportation and remote sensing of particles, as well as for particle capture or rejection. These conclusions are based on experimental studies (e.g. Frost 1972, Poulet 1978, Poulet \& Marsot 1978, Koehl \& Strickler 1981, Price et al. 1983, Yule \& Crisp 1983, Buskey 1984, Price \& Paffenhöfer 1986) and conceptual models (e.g. Rubenstein \& Koehl 1977, Andrews 1983, Legier-Visser et al. 1986, Poulet et al. 1986). Even though for calanoid copepods the methods of food capture for 'large' particles are understood (10 to $28 \mu \mathrm{m}$; Price et al. 1983), the method of capturing 'small' particles $(<6 \mu \mathrm{m}$; Price et al. 1983, Price \& Paffenhofer 1985) and the sensory mechanisms of food selection for both large and small cells (mechano- or chemoreception; e.g. Andrews 1983, Buskey 1984, Legier-Visser et al. 1986, Poulet et al. 1986) are still poorly understood. This deserves further investigation by direct observations of filter-feeding copepods using ciné or video cameras, or the microimpedance technique (Cowles \& Strickler 1983, Price et al. 1983, Yule \& Crisp 1983, Gill \& Poulet 1986, Gill 1987).

In the present study, a computer micro-impedance system was used to study the movements of the cephalic appendages of copepods in the presence of various particles and chemicals. Spectral analyses of 
the recordings were used to investigate the sensory mechanism involved in copepod feeding.

\section{MATERIALS AND METHODS}

Copepods were collected from the English Channel off Roscoff (France) and kept overnight at 12 or $15^{\circ} \mathrm{C}$ in filtered seawater. The beat patterns of the second antennae (A 2) and mandibular palps (Mdp) of Calanus helgolandicus were recorded in filtered seawater (Millipore, $0.45 \mu \mathrm{m}$ size filters). The first maxillae (M1) movements were recorded under similar conditions for comparison between $C$, helgolandicus, Centropages typicus and Temora longicornis. The effect of mechanosensory (particles) and chemosensory (amino acids) stimulations on the M1 movements of individual $T$. longicornis were also recorded. The experimental system incorporated a flow-through chamber receiving filtered seawater (control) initially, followed by filtered seawater to which stimulatory compounds were added (experiment). Recordings were made in a Perspex flow chamber of $125 \mathrm{ml}$ volume. Copepods were restrained by suction tubes in a water flow of $0.17 \mathrm{~cm} \mathrm{~s}^{-1}$, which was maintained at 10 or $15^{\circ} \mathrm{C}$. Details of the suction restraint method, of the flow chamber and of the impedance technique have been previously described (Yule \& Crips 1983, Gill \& Poulet 1986, Gill 1987).

Limb beat traces were selected from recordings of 1 to 3 min duration from 5 to 10 individuals of each species. Sections of traces (time series corresponding to 256 to 1300 data points, with $y=$ comparative amplitude [ $\mathrm{mV}$ ] and $x=$ time [ms] of the appendage movements; Yule \& Crisp 1983, Gill 1987) were treated, using spectral and autocorrelation analyses (Bendat \& Piersol 1971). Standard Fourier series procedure (Goertzel 1960) was followed, and the SSP-IBM 1130 package was used, without any initial data screening or smoothing, to describe and compare the traces in terms of frequency in the 1 to $100 \mathrm{~Hz}$ range.

\section{RESULTS}

\section{Normal limb beat patterns of Calanus helgolandicus}

Direct recordings of Calanus helgolandicus A2 and Mdp beating in filtered seawater are shown in Fig. 1 (left). Because of the similarity between the movements of the A2, Mdp, first maxillae (M1) and maxilliped (Mxp), and the absence of movements by the first antennae (A1) and second maxillae (M2) in particlefree seawater (Gill \& Poulet 1986), the traces of these latter appendages have been omitted from Fig. 1 C. helgolandicus limb beat patterns are characterized by beating and resting periods of varying duration. This activity is probably related to the 'hop and sink' swimming pattern reported by Cannon (1928).

Traces of cephalic appendage movements provide a suitable time series for spectral analysis. This statistical approach, based on Fourier analysis, discriminates the frequencies constituting a movement. It is a tool for studying the frequency of these oscillatory movements which is the most accurate parameter measured with the computerized micro-impedance system (Gill \& Poulet 1986, Gill 1987). Results in Fig. 1 are based on time series, each of which includes 400 to 700 data points (corresponding to beating periods designated by $\mathrm{S}$ [start] and $\mathrm{E}$ [end]; Fig. 1, left) so that frequencies in the range of 1 to $100 \mathrm{~Hz}$ can be discriminated. The power spectrum curve shows one peak $\left(\mathrm{V}^{2} / \mathrm{Hz}\right.$, where $V=$ amplitude in $\mathrm{mV}$ and $\mathrm{Hz}=$ frequency in cycles $\mathrm{s}^{-1}$ ) with height between $10^{-7}$ and $10^{-6}$, and frequency ranging from 29.9 to $28.7 \mathrm{~Hz}$, depending upon the appendage. The homogeneity of the beating period of these appendages is also demonstrated by autocorrelation analyses of the same time series (Fig. 1, left). The oscillatory movements, given for the mandibular palp as an example (Fig. 1, left: $\mathrm{S}-\mathrm{E}$ ), are autocorrelated for $K$ ranging from 0 to $>100$ (where $K=$ rank of data point in the time series), with a significant coefficient of correlation $(-0.85<r<+1$; $p=0.05)$.

\section{Comparison between copepod species}

The normal limb beat patterns of 3 species of copepods (Calanus helgolandicus, Centropages typicus and Temora longicornis), restrained in filtered seawater under similar experimental conditions, are compared in Fig. 2A. Recordings for the first maxillae (M1) showed differences related to the presence or absence of breaks during beating. $C$. helgolandicus and $C$. typicus are intermittent beaters, whereas $T$. Iongicornis is a continuous beater. The comparative amplitudes of the movements ( 5 to $25 \mathrm{mV}$ in Fig. 2A) may be related to appendage size and setal length. The amplitude of the beats for the larger $C$. helgolandicus was greater than for $C$. typicus and $T$. longicornis. This size/amplitude relationship is probably related to the energy expended in feeding and swimming, and subsequently to copepod metabolism.

Spectral analyses of M1 movements (time series of 500 to 768 data points) are shown for each species in Fig. 2B. The power spectrum curve, for each species, has one major peak (ranging from $10^{-8}$ to $10^{-7}$ ) above the background noise $\left(<10^{-10}\right)$. Under the experimental conditions, beat frequency was lowest for Temora longicornis $(21 \mathrm{~Hz})$, highest for Centropages typicus $(36.5 \mathrm{~Hz})$ and intermediate for Calanus helgolandicus 

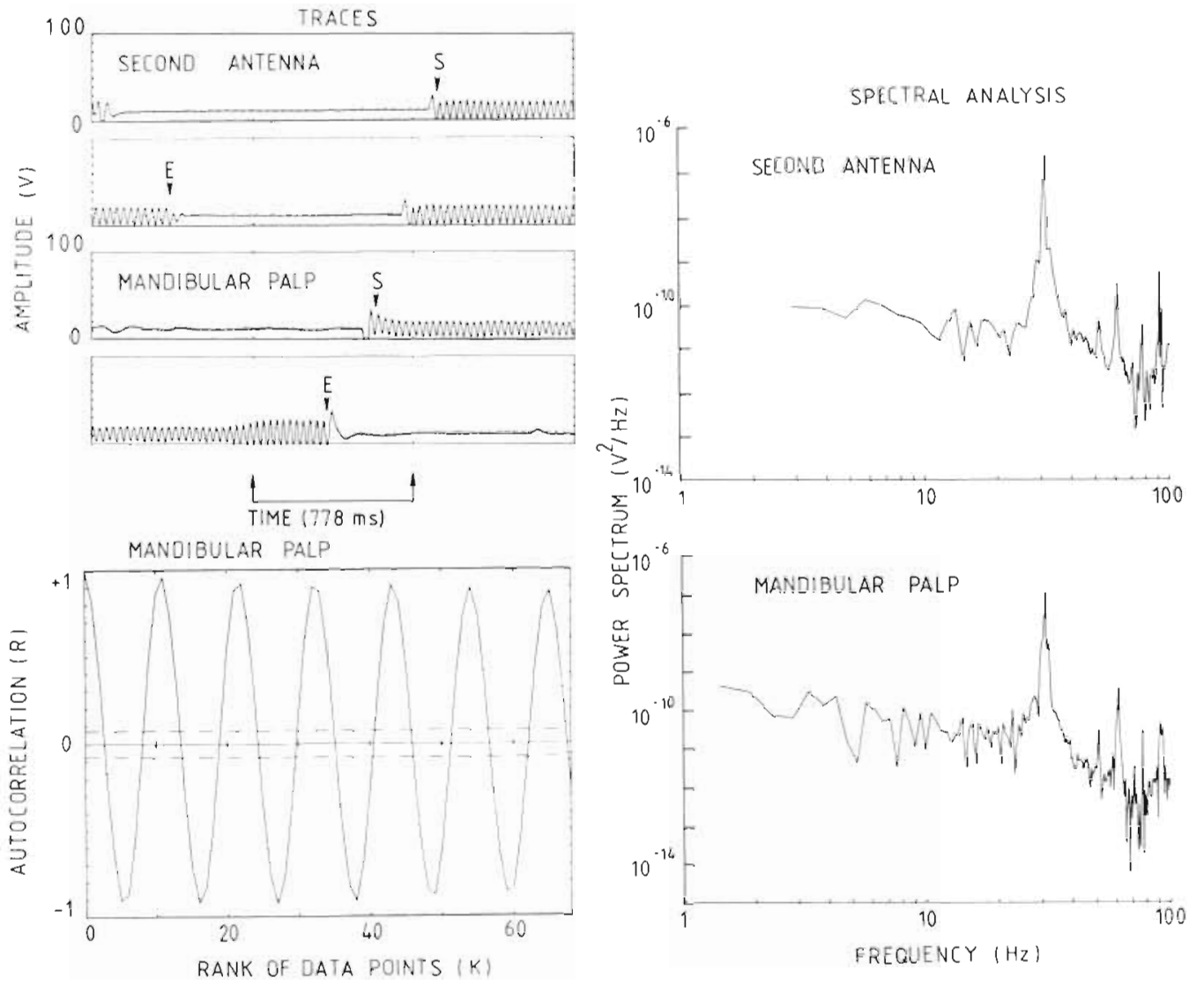

Fig. 1. Calanus helgolandicus. Normal limb beat patterns in filtered seawater. Top left: Traces of beating-resting periods. Right: Spectral analysis of the traces ( $\log / \log$ scales). Bottom left: Autocorrelation analyses of the traces of the mandibular palp. Appendages are: A2, second antenna; Mdp, mandibular palp. S and $E$ : start and end of time series studied by spectral and autocorrelation analyses. Units: $V$, amplitude in millivolts; $H z$, frequency in cycles per second; $K$, rank of data points in time series; $R$, coefficient of correlation. Dashed line: confidence limits $(p=0.05)$. Time unit (778 ms) corresponds to recordings of 256 data points

$(27.4 \mathrm{~Hz})$. The change in appendage beat frequency is species-dependent and related to copepod feeding and swimming behaviour, in addition to energy expenditure.

\section{Mechanosensory stimulation with beads}

Sephadex beads are hard, artificial particles, probably with a limited stimulatory effect on copepods, except size effect. The mechanosensory response of Temora longicornis offered unmeasured concentrations of Sephadex beads differing in size is shown in Fig. 3B. The normal limb beat pattern (control) was modified when copepods received beads dispensed by a micro-injector. In the presence of 'small' beads $(<20 \mu \mathrm{m} ;$ Fig. 3A, SM $)$, irregular beats of low amplitude were frequent (arrows). With 'medium' beads ( 20 to $40 \mu \mathrm{m}$; Fig. $3 \mathrm{~A}, \mathrm{M}$ ), changes in the pattern and resultant traces were characterized by beating periods showing succession of beats of low $(<5 \mathrm{mV})$ and high (10 to $20 \mathrm{mV}$ ) amplitudes. In the presence of 'large' beads ( 40 to $80 \mu \mathrm{m}$; Fig. 3A, L), the initial limb beat pattern was strongly modified; with beats having a higher amplitude (up to $20 \mathrm{mV}$ ) alternating with longer resting periods.

Spectral analyses of traces for small, medium and large Sephadex beads (time series $S$ to $E$ in Fig. 3A) gave different results (Fig. 3B). The values of the peaks of the power spectrum curves $\left(V^{2} / \mathrm{Hz}\right)$, ranged from $10^{-9}$ to $>10^{-8}$, and were above the background noise level $\left(\leqslant 10^{-10}\right)$. They were inversely proportional to particle sizes and varied according to the beating frequencies. The major peak occurred at $27 \mathrm{~Hz}$ for small beads and $4.5 \mathrm{~Hz}$ for large beads (Fig. 3B; SM and L). For medium sized beads, 3 peaks $\left(>8 \times 10^{-10}\right)$ were discriminated at 27, 25, and $22 \mathrm{~Hz}$ (Fig. 3B; M: arrows).

Autocorrelation analyses (Fig. 3C; SM, L) confirm the variations of the frequency of M1 movements, compared to control, when copepods handled beads of different sizes. Coefficients of correlation were significant $(p<0.05)$ for various values of $K$. In conclusion, 

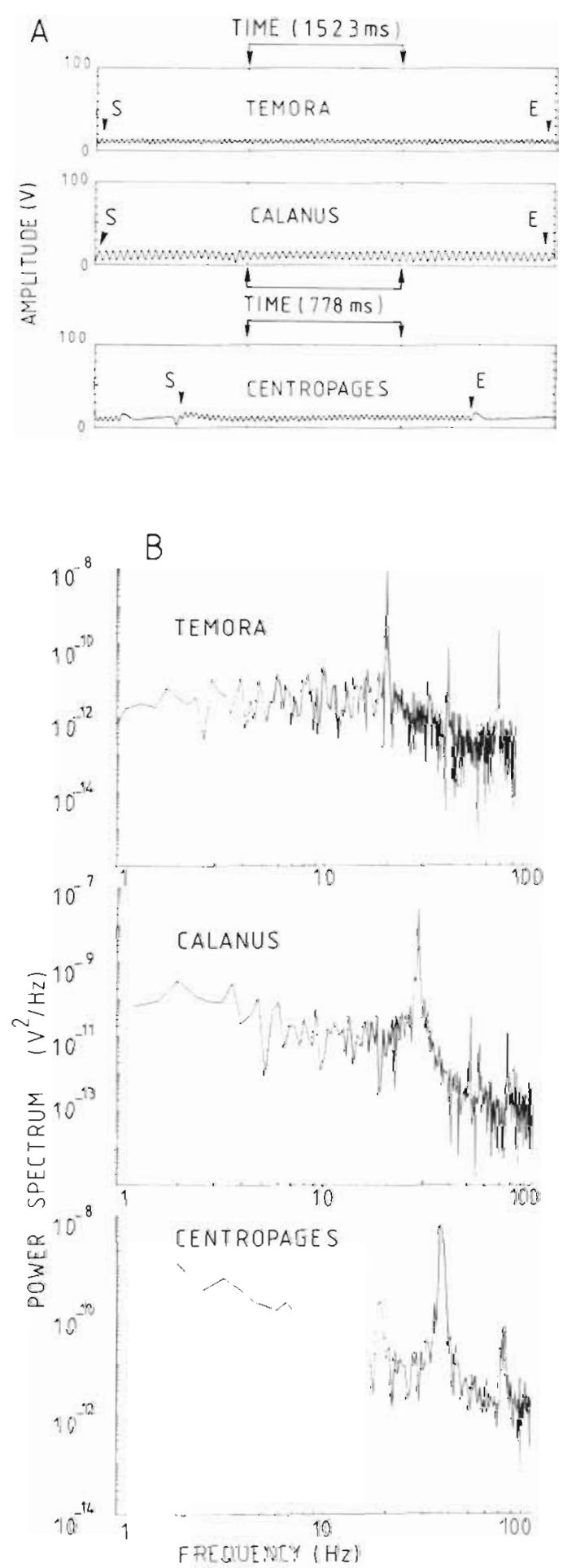

Fig. 2. Calanus helgolandicus, Centropages typicus and Temora longicornis. (A) Comparison of normal limb beat patterns of first maxillae (M1) among 3 species of copepods restrained in filtered seawater $S$ and $E$ : start and end of times series studied with spectral analysis. Time unit (778 or $1523 \mathrm{~ms}$ ) corresponds to recordings of 256 data points. (B) Spectral analysis of first maxillae (M1) movements for 3 species of copepods. Data analysed are shown in (A). V: amplitude of movements $(\mathrm{mV})$; $\mathrm{Hz}$ : frequency in cycles per second results in Fig. 3A, B and C show that mechanical stimulation alone, as given by the different sizes of artificial particles, is well perceived by copepods. The transition from particle-free seawater (control) to particleenriched seawater (experiment) modifies the frequency of the movements of the feeding appendages (Fig. 3B: control, SM). Switching from small to large beads induces decrease in frequency of the movements (Fig. 3A, B, C). These behavioural modifications do not seem to be a problem for Temora longicornis. Catching and handling beads is fast, ranging from 10 to $>100 \mathrm{~ms}$, depending on bead size (Fig. 3A). This type of stimulation strongly modified the filter-feeding behaviour of $T$. longicornis.

During the course of these recordings (Fig. 3A; SM, $M, L$ ), the movements of the feeding appendages were observed, using a Wild binocular microscope. The visual observations confirmed that the traces in Fig. 3A correspond to particle handling by copepods. All beads within the 10 to $80 \mu \mathrm{m}$ size range were captured, handled and transferred towards the mouth, by cooperative movements of the Mdp, M2, M1 and the flow of the feeding current. The majority of the beads, small and large, were rejected after handling. This complex behaviour has already been described in detail (e.g. Koehl \& Strickler 1981, Price et al. 1983). New information from results in Fig. 3(A, B, C) is: (1) frequency of M1 beating periods increases when copepods switch from particle-free to particle-enriched seawater (Yule \& Crisp 1983, Gill \& Harris 1987; Fig. 3); (2) during particle handling, beating frequency decreases in accordance with particle size ${ }_{i}(3)$ handling time increases with particle size; (4) handling time reflects 'tactile sensing' of particles by copepods. After a handling period, the limb beat pattern returns to normal (not shown in Fig. 3).

\section{Mechanosensory stimulation with natural particles}

Copepods do not normally feed on Sephadex beads; thus, conclusions derived from results in Fig. 3 may be unrealistic or irrelevant to natural feeding behaviour. Experiments involving natural food (suspendend particles and phytoplankton cultures) were used to verify findings obtained with artificial beads.

In the first series of experiments, Temora longicornis was offered seston collected at the same place and time as the copepods. The living fraction of the particle stock was essentially Rhizosolenia sp. (20 to $40 \mu \mathrm{m}$, spherical diameter), mixed with non-living particles of smaller and larger sizes $(<150 \mu \mathrm{m})$. Traces of copepods in filtered seawater were used as a control (Fig. 4, upper). Normal limb beat patterns were modified in the presence of seston (Fig. 4, centre; arrows). Traces were 


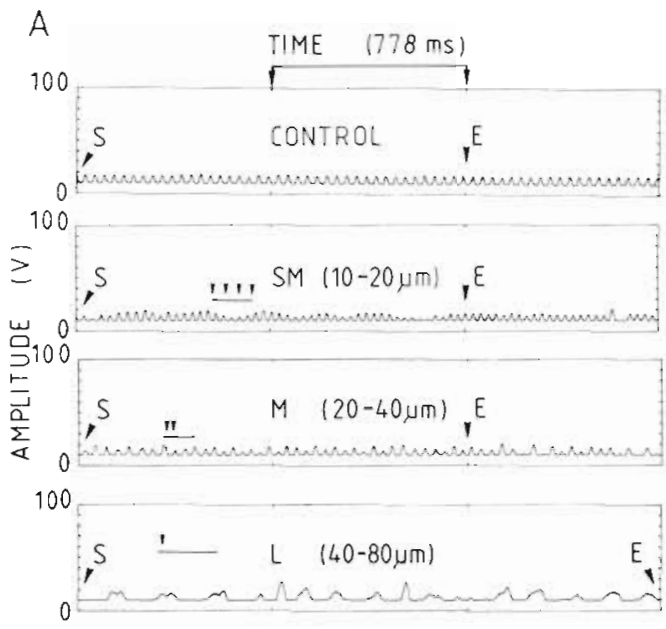

Fig. 3. Temora longicornis. Mechanosensory stimulation with Sephadex beads. (A) Trace of first maxillae (M1) movements in filtered seawater (Control); in filtered seawater containing small (SM: 10 to $20 \mu \mathrm{m}$ ), medium (M: 20 to $40 \mu \mathrm{m}$ ) and large (L: $40-80 \mu \mathrm{m}$ ) beads. $S$ and $E$ : start and end of time series studied by spectral and autocorrelation analyses. Arrows: handling periods. Time unit $(778 \mathrm{~ms})$ corresponds to recordings of 256 data points. (B) Spectral analyses of first maxillae (M1) movements when receiving small (SM), medium (M) and large (L) Sephadex beads. Data analysed are shown in (A) ( $S$ to $E$ ). $H$ : harmonic of the major peak. $V$ and $\mathrm{Hz}$ : as in Fig. 1. (C) Autocorrelation analyses for the traces of the first maxillae (M1) movements when receiving Sephadex beads of various sizes. SM, M, L and data same as in (A). $K$ and $R$ : as in Fig. 1. Dashed lines: confidence limits $(p=0.05)$

characterized by beating periods of high and low amplitudes, varying from 5 to $10 \mathrm{mV}$.

In the second series of experiments, Temora longicornis received phytoplankton culture cells (Thalassiosira sp., $20 \mu \mathrm{m}$ ). Traces of M1 movements, reflecting feeding behaviour, were recorded and compared with the control (Fig, 4). Modifications, similar to those obtained with $T$. longicornis receiving beads and seston of identical size ranges, corresponded to handling behaviour (Fig. 4, bottom; arrows). Visual observations of copepod feeding behaviour at the time of recording confirmed that food particles were handled for the same period of time; but, in contrast to Sephadex beads, cells of phytoplankton from cultures or from seston were ingested.

Spectral and autocorrelation analyses of traces of copepods feeding on seston and on phytoplankton cultures gave results (Fig. 5 and 6) resembling those obtained for copepods handling Sephadex beads of similar sizes (Fig. 3 and 4 ).
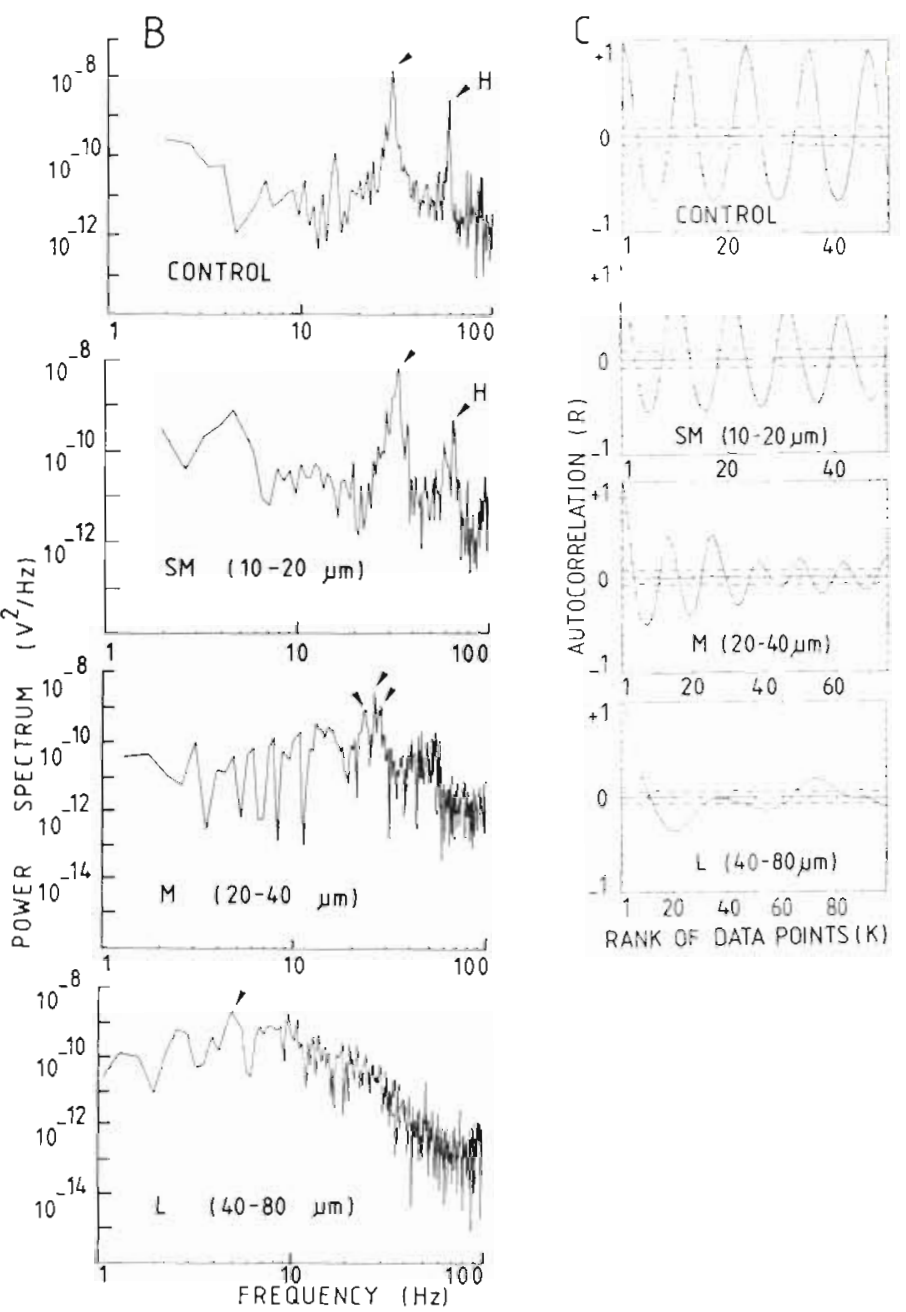

\section{Chemosensory stimulation of amino acids}

Biochemical compounds surrounding or leaking from living phytoplankton cells, or extracts of cells, have been suspected of being stimulatory agents for some time (e.g. Bainbridge 1953) allowing remote sensing of food by copepods. Copepods discriminate between food and non-food particles using chemoreception, and this was first demonstrated by Poulet \& Marsot (1978). Poulet and co-workers (Poulet \& Marsot 1980, Poulet \& Ouellet 1982, Gill \& Poulet 1988) further showed that amino acids can play a role in the feeding and swimming behaviour of copepods. In order to compare chemical and mechanical stimulations of copepods, recordings of the M1 movements of Temora longicornis receiving filtered seawater enriched with cocktails of amino acids (Sigma Co.) were made using the computerized micro-impedance system. Copepods received successively filtered seawater (control) and cocktails of equimolar concentrations of glycine, 


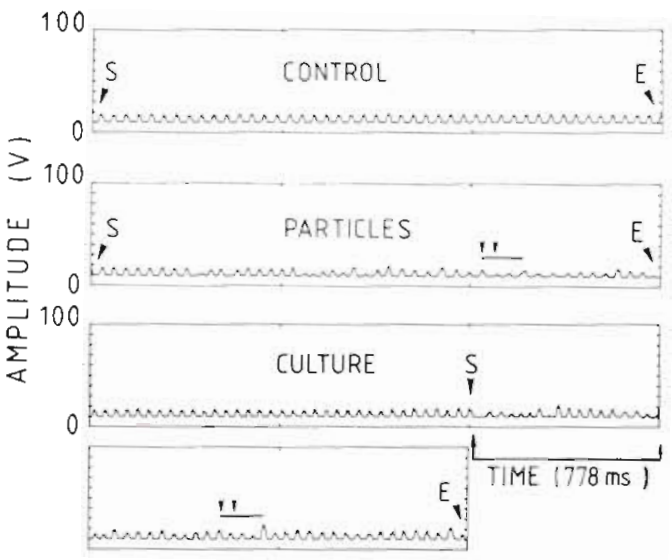

Fig. 4. Temora longicornis. Mechanical stimulation with food particles. Top: Control (filtered seawater). Centre: Naturally occurring particles $(<150 \mu \mathrm{m})$. Bottom: Phytoplankton culture (Thalassiosira $\mathrm{sp} . ; 20 \mu \mathrm{m}$ ). Traces of first maxillae (M1) beating patterns under control and experimental conditions. Arrows: handling periods. S and E: start and end of time series studied by spectral and autocorrelation analyses. Time unit $(778 \mathrm{~ms}$ ) corresponds to recordings of 256 data points

tyrosine, phenylalanine, leucine, ornithine and lysine $\left(10^{-6} M\right)$. Background levels of amino acids in filtered seawater $\left(10^{-9}\right.$ to $\left.10^{-8} M\right)$, estimated by high performance liquid chromatography (Lindroth \& Mopper 1979), were below the concentration used in experiments.

M1 traces for the control and experiment look the same (Fig. 7, left). Spectral analyses of selected time series (marked by $S$ and $E_{i}$ corresponding to 1280 data

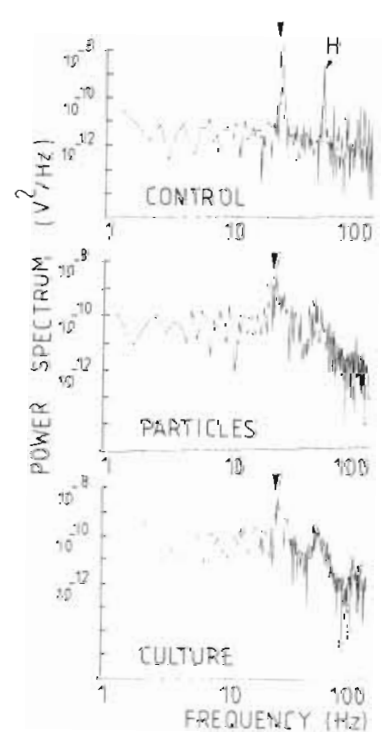

Fig. 5. Temora longicornis. Spectral analyses of first maxillae (M1) movements when feeding on natural particles. Data same as in Fig. 4. Top: Control (filtered seawater). Centre: Naturally occurring particles. Bottom: Phytoplankton culture (Thalassiosira sp.). H: harmonic of the major peak

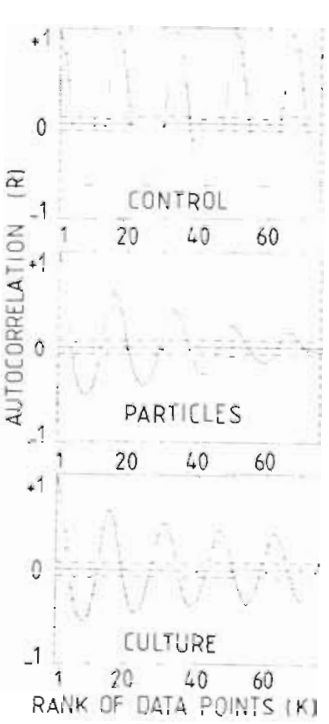

Fig. 6. Temora longicornis. Autocorrelation analyses of time series (marked by $\mathrm{S}$ and $\mathrm{E}$ in Fig. 4). $R$ and $K$ as in Fig. 1. Top: control. Centre: Naturally occurring particles (20 to $40 \mu \mathrm{m}$; $<150 \mu \mathrm{m})$. Bottom: Phytoplankton culture (Thalassiosira sp.;

$\sim 20 \mu \mathrm{m})$. Dashed lines: confidence limits $(p=0.05)$

points) show however that there are differences (Fig. 7 , right). Significant increases in frequency $(>7 \mathrm{~Hz})$ between the control and experimental conditions show that chemosensory stimulation alone, in the form of amino acids added to seawater, modifies the frequency of appendage movements; and thus, stimulates the beating speed of the appendages, but not the amplitude or the type of movement. Further details of the responses of Temora longicornis to amino acids cocktails are reported in the companion article (Gill \& Poulet 1988).

\section{DISCUSSION}

Copepod feeding has received considerable attention due to its pivotal role in the marine food web. The computerized micro-impedance system adds detailed information on feeding behaviour and reinforces our concepts resulting from previous microcinematographic, video and Coulter Counter observations. New results from the micro-impedance technique are related to: (1) quantitative measurements of limb beat patterns in terms of amplitude, frequency and duration; (2) detailed statistical studies of behavioural movements through spectral and autocorrelation analyses; (3) determination of resting-beating periods and handling time which change in relation to the size of particles; (4) effects of the stimulatory properties of chemical compounds such as amino acids (Gill \& Poulet 1988) 
Fig. 7. Temora longicornis. Chemical stimulation with dissolved amino acids $10^{-6} \mathrm{M}$. Left: Traces of first maxillae (M1) movements in filtered seawater (control) and in cocktails of 6 amino acids (GLY, TYR, PHE, LEU, ORN, LYS) dissolved in filtered seawater. $S$ and E: start and end of time series studied with spectral analysis. Right: Spectral analyses of time series obtained under control and experimental conditions

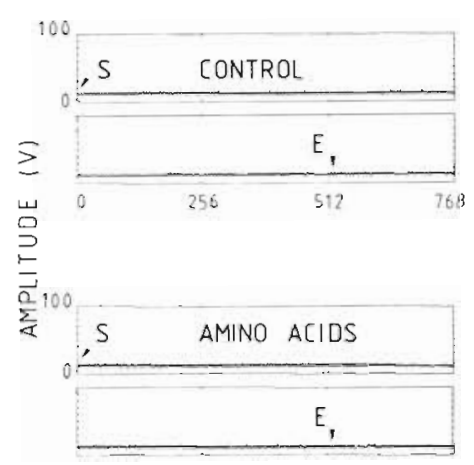

NUMBER OF DATA POINTS

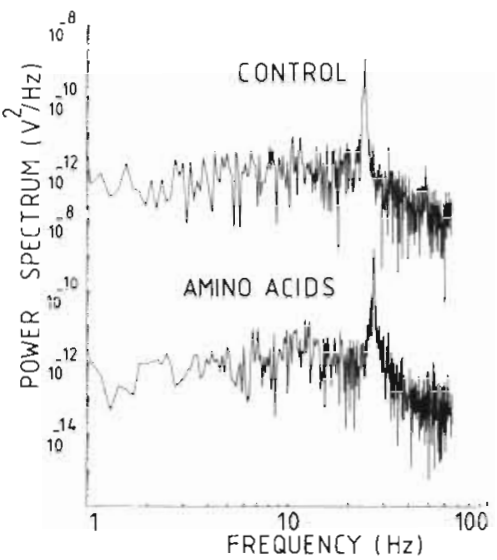

Our results (Fig. 3 to 7 ) imply that mechano- and chemosensory feeding behaviours in copepods are acting in conjunction. Buskey (1984) reached similar conclusions with Pseudocalanus minutus. In previous studies, each mechanism has been considered separately as if antagonistic. Copepods receive information from their environment in the form of physical and chemical stimulation and are equipped with both mechano- and chemoreceptors (Friedman 1980, Gill 1986). On that basis, we do not see why they should not react simultaneously to both type of signals. Moreover, it is conceivable that both modes of reception acting together could enhance feeding efficiency of copepods, thereby constituting a major strategy for survival in a nutritionally dilute environment (Conover 1968).

Our results are consistent with those obtained for other species of copepods (Alcaraz et al. 1980, Koehl \& Strickler 1981, Price \& Paffenhöfer 1984, 1985, 1986). Feeding behaviour on small particles (e.g. particles $<6$ to $10 \mu \mathrm{m}$; Koehl \& Strickler 1981, Price \& Paffenhöfer 1985 ) has yet to be properly observed and understood using any of the recent techniques, even though copepods are known to ingest particles $<10 \mu \mathrm{m}$ (e.g. Frost 1972, Poulet 1978, Donaghay \& Small 1979, Price \& Paffenhöfer 1983). We have investigated the behavioural responses of copepods within a broad size range (10 to $80 \mu \mathrm{m})$, using artificial and natural particles. Among the particulate food eaten by copepods, this range corresponds to microplankton ( $>20 \mu \mathrm{m}$; while nanoplankton is $<20 \mu \mathrm{m})$. Both are food stocks differing in production rates and nutritional values (Mullin 1965, Strathmann 1967, Moal et al. 1987). The problem of whether consuming a few large particles is more efficient and advantageous than consuming many small ones is important in copepods (e.g. Frost 1972,1977 ). It is generally accepted that calanoid copepods filter-feed on small particles less efficiently. From results shown in Figs. 4 and 5, and from other experiments using phytoplankton cultures of similar sizes (Gill \& Harris 1987), it is obvious that handling time does not depend upon size alone. Therefore we believe that feeding efficiency of copepods with regard to particle size may be due to differential 'tactile sensing' of particles. Particle handling allows copepods to taste and select food (Fig. 3 to 6; Huntley et al. 1983, Price \& Paffenhöfer 1985). Handling indirectly modifies absolute feeding efficiency (e.g. number of nutritious particles captured per unit of time). Handling time measured for Temora longicornis can be short (10 to $<100 \mathrm{~ms}_{i}$ Figs. 3 to 5; Koehl \& Strickler 1981). Copepods spend more time handling large particles. Thus, it is probably more efficient for then to catch and sense large particles than small particles. Consequently, the probability of ingesting large particles is high. However, the nutritional value of particles is not related to their size, but rather to the ratio of food amount to cell volume. Poulet et al. (1986) and Harris et al. (1986) have shown that for zooplanktonic crustaceans, ingestion rates of proteins and carbohydrates are related both to feeding rates and concentration of the chemical per cell. In addition, small cells of phytoplankton have a higher nutritional value per unit volume than large cells (Mullin 1965, Strathmann 1967, Moal et al. 1987). When the independent parameters which are listed above are considered together, they constitute a strategy for optimizing feeding efficiency in copepods.

Phytoplankton extracts contain stimulatory agents whose chemical nature is generally unknown (Bainbridge 1953, Poulet \& Marsot 1978, Huntley et al. 1983. Buskey 1984, Gill \& Harris 1987). Results obtained by Poulet \& Marsot (1980), Poulet \& Ouellet (1982), Gill \& Poulet (1988) and present results on the variability in the frequency of M1 movements of Temora longicornis (Fig. 7), demonstrate that amino acids are: (1) stimulatory chemicals for copepods; (2) acting at the remote scales; and (3) influence swimming and feeding behavioural patterns. They are actually the only com- 
pounds found in phytoplankton known to stimulate copepod behaviour.

Various physical and chemical factors could stimulate swimming and feeding; however, it appears that particle size and amino acids are essential factors determining mechano- and chemosensory behaviour of copepods. Therefore, they are key factors in the swimming and feeding patterns of copepods.

Acknowledgements. C. W. Gill gratefully acknowledges receipt of a Royal Society of London post-doctoral fellowship in the European Science Exchange Programme. Thanks are due to D. Evans, D. Guillou, H. Lemoal for their assistance in setting up the electronic system; C. Le Roux and J. L. Douville for computing assistance. This work is a contribution of CNRS (Incitation Europe and DRCI contract nos. 8650N5072 and 8692N920198) and of GREPMA (Groupe Regional d'Etudes Pelagiques Manche-Atlantique). Thanks are due to Drs R. P. Harris and D. Vaulot and referees for their positive comments and corrections.

\section{LITERATURE CITED}

Alcaraz, M., Paffenhöfer, G. A, Strickler, J. R. (1980). Catching the algae: a first account of visual observations of filterfeeding calanoids. In: Kerfoot, W C. (ed.) Evolution and ecology of zooplankton communities. University Press of New England, Hanover, p. 241-248

Andrews, J. C. (1983). Deformation of the active space in the low Reynolds number feeding current of calanoid copepods. Can. J. Fish. aquat. Sci. 40: 1293-1302

Bainbridge, R. (1953). Studies on the interrelationships of zooplankton and phytoplankton. J. mar. biol. Ass. U. K. 32: 385-447

Bendat, J. S., Piersol, A. G. (1971). Random data. Analysis and measurement procedures. Wiley, London

Boyd, C. M. (1976). Selection of particle sizes by filter-feeding copepods: a plea for reason. Limnol. Oceanogr 21: $175-180$

Buskey, E. J. (1984). Swimming pattern as an indicator of the roles of copepod sensory systems in the recognition of food. Mar. Biol. 79: 165-175

Cannon, H. G. (1928). On the feeding mechanism of the copepods, Calanus finmarchicus and Diaptomus gracilis. Br J. exp. Biol. 6: 131-144

Conover, R. J. (1966). Feeding on large particles by Calanus hyperboreus (Kroyer). In. Barnes, H. (ed.) Some contemporary studies in marine science. Allen and Unwin, London, p. 187-194

Conover, R. J. (1968). Zooplankton life in a nutritionally dilute environment. Am. Zool. 8: 107-118

Cowles, T J., Strickler, J. R. (1983). Characterization of feeding activity in the planktonic copepod Centropages typicus Krøyer under various food conditions. Limnol. Oceanogr. 28: 106-1115

Donaghay, P. L., Small, L. F. (1979). Food selection capabilities of the estuarine copepod Acartia clausi. Mar Biol. 52: $129-146$

Esterly, C. O. (1916). The feeding habits and food of pelagic copepods and the question of nutrition by organic substances in solution in the water. Univ. Calif. Publs Zool. 16: $171-184$

Friedman, M. M. (1980). Comparative morphology and functional significance of copepod receptors and oral structures. In: Kerfoot, W. C. (ed.) Evolution and ecology of zooplankton communities. University Press of New England, Hanover, p. 185-197

Frost, B. W. (1972). Effects of size and concentration of food particles on the feeding behavior of the marine planktonic copepopd Calanus pacificus. Limnol. Oceanogr. 17. $805-815$

Frost, B. W. (1977). Feeding behavior of Calanus pacificus in mixtures of food particles. Limnol. Oceanogr. 22: 427-491

Gill, C. W. (1986). Suspected mechano- and chemosensory structures of Temora longicornis (Copepoda: Calanoida). Mar. Biol. 93: 449-457

Gill, C. W. (1987). Recording the beat patterns of the second antennae of calanoid copepods, with a micro-impedance technique. Hydrobiol. 148: 73-78

Gill, C. W., Poulet, S. A. (1986). Utilization of a computerized micro-impedance system for studying the activity of copepod appendages. J. exp. mar. Biol. Ecol. 101: 193-198

Gill, C. W., Harris, R. P. (1987). Behavioural responses of the copepods Calanus helgolandicus and Temora longicornis to dinoflagellate diets. J. mar. biol. Ass. U. K. 67: 785-801

Gill, C. W., Poulet, S. A. (1988). Responses of copepods to dissolved free amino acids. Mar. Ecol. Prog. Ser 43: 269-276

Goertzel, G. (1960). Fourier analysis. In: Ralston, A., Wilf, H. S (eds.) Mathematical methods for digital computers, Vol. 1. Wiley, New York, p. 258-262

Harris, R. P., Samain, J. F., Moal, J., Martin-Jezequel, V. Poulet, S. A. (1986). Effects of algal diet on digestive enzymes in Calanus helgolandicus. Mar. Biol. 90: 353-361

Huntley, M. E., Barthel, K. G., Star, J. L. (1983). Particle rejection by Calanus pacificus: discrimination between similarly sized particles. Mar. Biol. 74: 151-160

Koehl, M. A. R., Strickler, J. R. (1981). Copepod feeding currents; food capture at low Reynolds number. Limnol. Oceanogr. 26: 1062-1073

Legier-Visser, M. F., Mitchell, J. G., Okubo, A., Fuhrman, J A (1986). Mechanoreception in calanoid copepods. A mechanism for prey detection. Mar. Biol. 90: 529-535

Lindroth, P., Mopper, K. (1979). High performance liquid chromatography determination of subpicomole amounts of amino acids by precolumn fluorescence derivatization with o-phtaldialdehyde. Analyt. Chem. 51: 1667-1674

Moal, J., Samain, J. F., Harris, R. P., Martin-Jezequel, V. Poulet, S. A. (1987). Interspecific and intraspecific variability in the chemical composition of marine phytoplankton Oceanologica Acta 10: 339-346

Mullin, M. M. (1965). Size fractionation of particulate organic carbon in the surface waters of the western Indian Ocean Limnol. Oceanogr. 10: 459-462

Paffenhöfer, G.-A., Strickler, J. R, Alcaraz, M. (1982). Suspension-feeding by herbivorous calanoid copepods: a cinematographic study. Mar Biol. 67: 193-199

Parsons, T R., Lebrasseur, R. J., Fulton, J. P. (1967). Some observations on the dependence of zooplankton grazing on the cell size and concentration of phytoplankton bloom. J. oceanogr. Soc. Japan 23: 10-17

Poulet, S. A. (1978). Comparison between five coexisting species of copepods feeding on naturally occurring particulate matter Limnol. Oceanogr. 23: 1126-1143

Poulet, S. A., Marsot, P. (1978). Chemosensory grazing by marine calanoid copepods (Arthropoda: Crustacea). Science 200: 1403-1405

Poulet, S. A., Marsot, P. (1980). Chemosensory feeding and food-gathering by omnivorous marine copepods. In. Kerfoot, W. C. (ed.) Evolution and ecology of zooplankton communities. University Press of New England, Hanover, p. $198-218$ 
Poulet, S. A., Ouellet, G. (1982). The role of amino acids in the chemosensory swarming and feeding of marine copepods. J. Plankton Res. 4: 341-361

Poulet, S. A., Samain, J. F., Moal, J. (1986). Chemoreception and food requirements among copepods. In: Schreiver, G., Schminke, H. K., Shih, C. T (eds.) Proceedings 2nd International Conference on Copepoda. Syllogeus $N 58$, National Museum of Canada, Ottawa, p. 426-442

Price, H. J., Paffenhöfer, G. A., Strickler, J. R. (1983). Modes of cell capture in calanoid copepods. Limnol. Oceanogr 28 $116-123$

Price, H. J., Paffenhöfer, G. A. (1984). Effects of feeding experience in the copepod Eucalanus pileatus: a cinematographic study. Mar Biol. 84: 35-40

Price, H. J., Paffenhöfer, G. A. (1985). Perception of food availability by calanoid copepods. Arch. Hydrobiol. Beih Ergeb. Limnol. 21: 115-124

Price, H. J., Paffenhöfer, G. A. (1986). Effects of concentration on the feeding of marine copepod in algal monocultures and mixtures. J. Plankton Res. 8: 119-128

Rubenstein, D. I., Koehl, M. A. R. (1977). The mechanisms of filter-feeding: some theorical considerations. Am. Nat. 111-981-994

Strathmann, R. R. (1967). Estimating the organic carbon content of phytoplankton from cell volume or plasma volume. Limnol. Oceanogr, 12: 411-418

Strickler, J. R. (1982). Calanoid copepods, feeding currents and the role of gravity. Science 218: 158-160

Vanderploeg, H. A., Paffenhöfer, G.-A. (1985). Modes of algal capture by the freshwater copepod Diaptomus sicilis and their relation to food-size selection. Limnol. Oceanogr. 30: $871-885$

Yule, A. B., Crisp, D. J. (1983). A study of feeding behaviour in Temora longicornis Müller (Crustacea: Copepoda). J. exp. mar Ecol. 17: 271-282

This article was submitted to the editor; it was accepted for printing on January 29, 1988 